\title{
Hypertensive Retinopathy: A Prognostic Factor for Morbidity and Mortality after Acute ST Elevation Myocardial Infarction
}

\author{
Muhammad Saad Jibran, Syed Abid Habib and Sher Bahadar Khan
}

\begin{abstract}
Objective: To determine the association between hypertensive retinopathy (HR) and post ST elevation myocardial infarction (STEMI) complications among successfully thrombolysed patients.

Study Design: A cohort study.

Place and Duration of Study: Cardiology Unit, Lady Reading Hospital, Peshawar, from June 2016 to December 2017. Methodology: Patients with history of hypertension for at least 5 years who presented with STEMI and were successfully thrombolysed, were included. On the basis of fundoscopy, patients were grouped into no, mild, moderate, and severe hypertensive retinopathy. Primary and secondary endpoints included a composite of death, re-MI, stroke, re-hospitalisation secondary to left ventricular failure, cardiogenic shock, arrhythmia, heart block, and ventricular septal rupture at 30 days and 4 months, respectively. Association between hypertensive retinopathy and post STEMI complications was determined by Chi-square test. Regression model was used to calculate relative risk of complications with hypertensive retinopathy. $P \leq 0.05$ was taken as significant.

Results: A total of 118 patients with a mean age of $54.83 \pm 8.6$ years were included in the study. Of these, $49.2 \%$ ( $n=58)$ were males. Moreover, 38.1\% $(n=45)$ of patients were grouped under no HR, 22.8\% ( $n=27)$ under mild HR, 21.1\% ( $n=25)$ and $17.7 \%(n=21)$ under moderate and severe HR, respectively. Primary endpoints achieved were $0 \%$ in no HR group and $19 \%$ in severe HR group $\left(\chi^{2}=18.1, p<0.001\right)$. Secondary endpoints were achieved in $2.2 \%$ in no HR group and $40.7 \%$, $56 \%$ and $100 \%$ in mild, moderate and severe HR group, respectively, $\left(\chi^{2}=81.1, p<0.001\right)$. HR also increased the relative risk of complications by 3.17 times $(p<0.001)$ and death by 1.75 times $(p<0.001)$.

Conclusion: Hypertensive retinopathy is an independent risk factor for post-acute STEMI complications in successfully thrombolysed patients and increased the relative risk for complications by 3.17 times.
\end{abstract}

Key Words: Hypertensive retinopathy (HR), ST elevation myocardial infarction (STEMI), Left ventricular failure (LVF), Cardiogenic shock (CS), Heart block (HB), Ventricular septal rupture (VSR).

\section{INTRODUCTION}

Hypertension has emerged as a major health problem in recent years worldwide.1,2 It is a top ranked cause of morbidity and mortality in developing countries with a projected prevalence to reach $30 \%$ of entire population by $2025 .{ }^{3}$ Sub-optimal blood pressure control results in a number of cardiovascular, cerebrovascular, renal, and retinal complications, often referred to as target organ damage. ${ }^{1}$ Elevated blood pressure opens a cascade of pathophysiological changes in retinal vasculature. 4 These changes then manifest as hypertensive retinopathy (HR). Signs of HR can be grouped into vascular changes including focal segmental arteriolar narrowing, diffuse arteriolar narrowing, artetiovenous (AV) nipping and opacification; and advanced changes including micro aneurysms, dot and blot hemorrhages, cotton wool spots, hard and soft exudates, and papilloedema. These signs can even be easily seen among persons without known history of hypertension. 5

Cardiology Unit, Lady Reading Hospital, Peshawar, Pakistan

Correspondence: Dr. Syed Abid Habib, Cardiology Unit,

Lady Reading Hospital, Peshawar, Pakistan

E-mail:docsyedabid@gmail.com

Received: April 03, 2018; Accepted: November 12, 2018
Microvascular subclinical damage in the form of retinopathy, or microalbuminuria with glomerular dysfunction precedes the major adverse complications like cerebrovascular accidents, myocardial infarction etc. $6,7 \mathrm{HR}$ has been advocated as a predictor of mortality and morbidity since long. ${ }^{8}$ Even the international guidelines of JNC and British Hypertension Society recommend the routine screening for signs of HR to risk stratify the patients. ${ }^{8}$ Data from recent studies demonstrate a $3-14 \%$ prevalence of signs of HR among patients above 40 years of age. 9 Wisconsin et al. showed the 5-year incidence of HR in a range of $6-16 \% .{ }^{10}$

This study was aimed to determine the association between HR and post STEMI complication rates among successfully thrombolysed patients to predict high risk patients requiring aggressive interventions.

\section{METHODOLOGY}

This prospective cohort study was conducted in Cardiology Unit, Lady Reading Hospital (LRH), Peshawar, from June 2016 to December 2017, after approval from the Hospital Ethical Review Board. All patients admitted to Cardiology Unit with acute STEMI and positive highly sensitive-Troponin $\mathrm{T}$, who were successfully thrombolysed and had history of hypertension for at least five years, were included in the study. After taking written informed 
consent detailed history was taken and records reviewed followed by physical examination to fulfill the exclusion criteria. Patients with a history of previous STEMI, percutaneous intervention or coronary artery bypass graft surgery, congenital heart disease, cardiac failure, cardiomyopathy, chronic liver or kidney disease, malignancy, diabetic retinopathy, cataracts, retinitis pigmentosa, pan retinitis, maculopathies, conjunctivitis, and other conjunctival diseases like pterygium and history of retinal photocoagulation were excluded from the study.

Patients were enrolled in this cohort study from June 2016 to December 2017 on the basis of successful thrombolysis after acute STEMI. These patients were observed for one month after inclusion in the cohort for primary endpoints, i.e. a composite of re-myocardial infarction, stroke, death and re-hospitalisation secondary to cardiogenic shock (CS), left ventricular failure (LVF), heart block, arrhythmia and ventricular septal rupture (VSR) or any of the above complications alone. Secondary endpoints were defined as a composite of the above complications or alone, occurring after one month till four months.

Data regarding baseline variables including age, gender, comorbid conditions, type of MI, systolic blood pressure (SBP), diastolic blood pressure (DBP), highly sensitiveTroponin $\mathrm{T}$, lipid profile at the time of admission, and medicines used for hypertension, were recorded. Fundoscopy was performed by two residents of cardiology for all the included patients under the supervision of a consultant ophthalmologist. The patients were categorised into 4 groups: no HR, mild HR (mild focal narrowing of vessels), moderate HR (diffuse narrowing of vessels with AV nipping, cotton wool spots and hemorrhages), and severe HR (papilloedema), on the basis of classification proposed by Keith et al. 11 Successful thrombolysis was defined as at least $50 \%$ resolution of ST elevations in ECG at 90 minutes of initiating the streptokinase infusion. Patients were followed on monthly basis for four months in outpatient department with review of records and a thorough examination followed by appropriate investigations, if needed, including ECG, echocardiography, chest X-ray, and CT brain to look for any complications.

Data regarding re-hospitalisation was obtained by interview and reviewing records. All the above mentioned information were recorded in a pre-designed proforma. All data were analysed with SPSS version 20.0. Mean $\pm S D$ was calculated for continuous variables. Frequencies and percentages were calculated for categorical variables. Association between hyper-tensive retinopathy and different complications was calculated by using Chi-Square test. Relative risk was calculated by using regression model. Kaplan-Meier survival curve was drawn for overall incidence of complications over four months and for death. A $p$-value of $\leq 0.05$ was taken as significant.

\section{RESULTS}

A total of 118 patients were recruited in the study with mean age of $54.83 \pm 8.6$ years, of which $49.2 \% \quad(n=58)$ were males. The mean duration of hypertension was $8.2 \pm 2.7$ years. Mean SBP and DBP were $132.7 \pm 36.2$ and $90.1 \pm 18.7 \mathrm{mmHg}$, respectively. Fifty-eight $(49.2 \%)$ patients were on calcium channel blockers, $33.1 \%$ $(n=39)$ on angiotensin converting enzyme inhibitors/ angiotensin receptor blockers, $9.3 \%(n=11)$ on beta blockers, and $8.4 \%(n=10)$ were using a combination therapy for BP control. Baseline characteristics of the included patients are given in Table I.

Primary composite endpoints at one month were achieved in $3.7 \%(n=1)$ of patients in mild HR group, $8 \%$ $(n=2)$ of patients in moderate HR group, and 19\% $(n=4)$

Table I: Baseline characteristics.

\begin{tabular}{l|c|c|c}
\hline Variables & $\begin{array}{c}\text { Mean } \pm \text { SD / Freq: } \\
(\%)\end{array}$ & Variables & $\begin{array}{c}\text { Mean } \pm \text { SD / Freq: } \\
(\%)\end{array}$ \\
\hline Age & $54.83 \pm 8.6$ & STEMI category & \\
\hline Male & $58(49.2 \%)$ & Anterior MI & $19(16.1 \%)$ \\
\hline Female & $60(50.8 \%)$ & Anterolateral MI & $36(30.5 \%)$ \\
\hline $\begin{array}{l}\text { Duration of } \\
\text { hypertension }\end{array}$ & $8.2 \pm 2.7$ years & $\begin{array}{c}\text { Anterior }+ \\
\text { Inferior MI }\end{array}$ & $3(2.5 \%)$ \\
\hline Diabetes mellitus & $49(41.5 \%)$ & Inferior MI & $13(11 \%)$ \\
\hline Smoking & $46(39 \%)$ & Lateral MI & $12(10.2 \%)$ \\
\hline Family history of CAD & $39(33.1 \%)$ & Inferoposterior MI & $12(10.2 \%)$ \\
\hline $\begin{array}{l}\text { Family history of } \\
\text { hypertension }\end{array}$ & $40(33.1 \%)$ & $\begin{array}{c}\text { avR } \uparrow \\
\text { Walcium channel }\end{array}$ & $10(8.5 \%)$ \\
\hline $\begin{array}{l}\text { blockers } \\
\text { ACEls / ARBs }\end{array}$ & $58(49.2 \%)$ & Posterior MI & $3(2.5 \%)$ \\
\hline Beta blockers & $11(9.3 \%)$ & TGs & $185.58 \pm 54.8(\mathrm{mg} / \mathrm{dl})$ \\
\hline Combination & $10(8.4 \%)$ & LDL & $123.6 \pm 28.8(\mathrm{mg} / \mathrm{dl})$ \\
\hline Systolic BP & $132.7 \pm 36.2$ & HDL & $40.3 \pm 4.5(\mathrm{mg} / \mathrm{dl})$ \\
\hline Diastolic BP & $90.1 \pm 18.7$ & Cholesterol & $199.1 \pm 25.0(\mathrm{mg} / \mathrm{dl})$ \\
\hline Fractional shortening & $26.7 \pm 2.3$ & & \\
\hline LV ejection fraction & $53.7 \pm 5.1$ & \multicolumn{2}{l}{} \\
\hline
\end{tabular}

Table II: Association of hypertensive retinopathy with complications.

\begin{tabular}{l|c|c|c|c|c|c}
\hline Variable & No HR & Mild HR & Mod HR & Severe HR & $X^{2}$ value & p-value \\
\hline \begin{tabular}{l} 
No. of patients \\
\hline $\begin{array}{l}\text { Primary } \\
\text { endpoints }\end{array}$
\end{tabular} & $0(38.1 \%)$ & $27(22.8 \%)$ & $25(21.1 \%)$ & $21(17.7 \%)$ & & \\
\hline $\begin{array}{l}\text { Left ventricle } \\
\text { failure }\end{array}$ & $1(2.2 \%)$ & $1(3.7 \%)$ & $2(8 \%)$ & $4(19 \%)$ & 18.1 & 0.001 \\
\hline $\begin{array}{l}\text { Cardiogenic } \\
\text { shock }\end{array}$ & 0 & $3(11.1 \%)$ & $4(16 \%)$ & $8(38 \%)$ & 15.8 & 0.001 \\
\hline Arrhythmia & 0 & $3(11.1 \%)$ & $7(28 \%)$ & $7(33.3 \%)$ & 17.6 & 0.001 \\
\hline $\begin{array}{l}\text { AV block } \\
2^{\text {nd degree }}\end{array}$ & 0 & 0 & $1(4 \%)$ & 0 & 16.1 & 0.001 \\
\hline CHB & 0 & $2(7.4 \%)$ & $2(8 \%)$ & $3(14.2 \%)$ & & \\
\hline $\begin{array}{l}\text { Ventricular } \\
\text { Septal rupture }\end{array}$ & 0 & 0 & $1(4 \%)$ & $2(9.5 \%)$ & 11.1 & 0.041 \\
\hline Stroke & 0 & 0 & $2(8 \%)$ & 0 & 7.5 & 0.056 \\
\hline $\begin{array}{l}\text { Death } \\
\text { Secondary } \\
\text { Endpoints }\end{array}$ & $1(2.2 \%)$ & $11(40.7 \%)$ & $14(56 \%)$ & $21(100 \%)$ & 81.1 & $<0.001$ \\
\hline
\end{tabular}


of patients in severe HR group. No adverse event was observed in no HR group.

Secondary endpoints at four months were achieved in $2.2 \%(n=1)$ of patients in no HR group, $40.7 \%(n=11)$ in mild HR group, $56 \%(n=14)$ in moderate HR group, and $100 \%(n=21)$ in severe HR group. The details are given in Table II.

Table III: Relative risk of complications with hypertensive retinopathy.

\begin{tabular}{l|c|c|c|c}
\hline Complication & RR & $\operatorname{Exp}(\mathrm{RR})$ & Cl Exp & $\mathrm{p}$-value \\
\hline Complications overall & 3.17 & 23.81 & $7.4-75.8$ & $<0.001$ \\
\hline Left ventricular failure & 1.75 & 5.78 & $3.2-10.3$ & $<0.001$ \\
\hline Arrhythmia & 1.05 & 2.88 & $1.63-5.07$ & $<0.001$ \\
\hline Cardiogenic shock & 0.73 & 2.09 & $1.2-3.5$ & 0.007 \\
\hline AV Block & 1.36 & 1.81 & $0.32-3.87$ & 0.019 \\
\hline Stroke & 0.64 & 1.91 & $0.51-3.91$ & 0.334 \\
\hline Ventricular septal rupture & 1.58 & 4.87 & $2.18-7.36$ & 0.086 \\
\hline Death & 1.75 & 5.8 & $2.57-9.12$ & $<0.001$ \\
\hline
\end{tabular}

Table IV: Multivariate analysis for association of hypertensive retinopathy and complication rates post-STEMI.

\begin{tabular}{l|c|c}
\hline Variable & $\mathrm{X}^{2}$ value & $\mathrm{p}$-value \\
\hline $\begin{array}{l}\text { Diabetes mellitus } \\
\text { Yes }\end{array}$ & 36.7 & $<0.001$ \\
No & 43.5 & $<0.001$ \\
\hline Sex & 39.47 & $<0.001$ \\
$\quad$ Male & 44.44 & $<0.001$ \\
$\quad$ Female & & \\
Smoking & 44.49 & $<0.001$ \\
Yes & 48.20 & $<0.001$ \\
No & & \\
\hline Family history & 49.81 & $<0.001$ \\
Yes & 54.66 & $<0.001$ \\
No & &
\end{tabular}

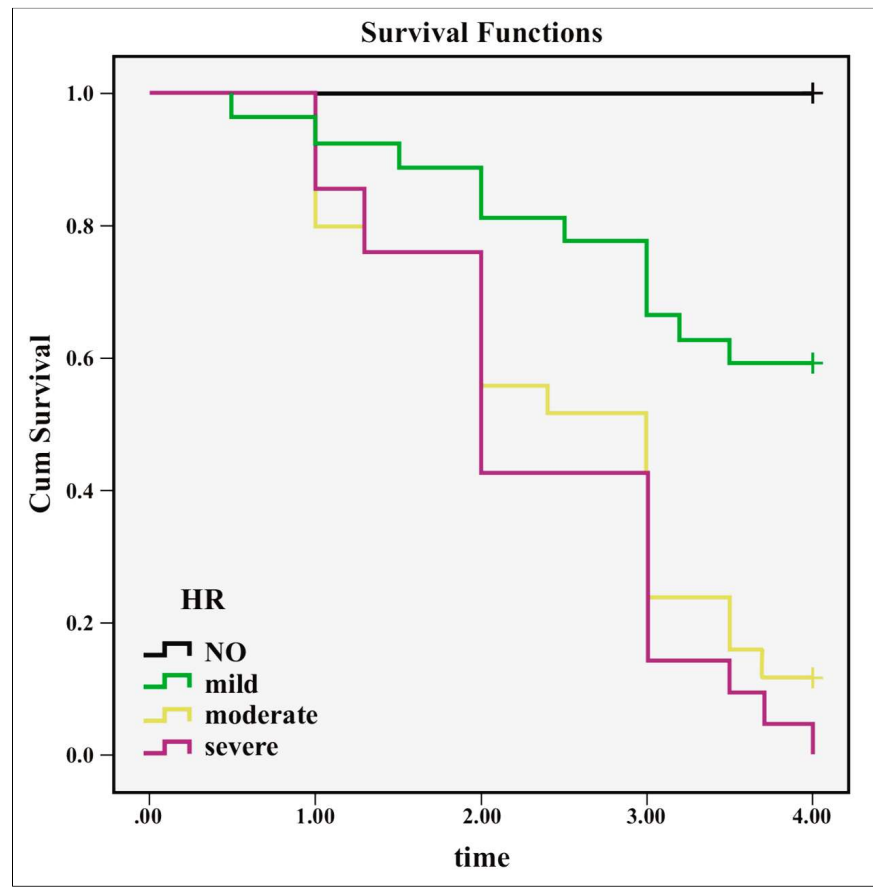

Figure 1: Kaplan-Meier curve for survival against hypertensive retinopathy and complications.

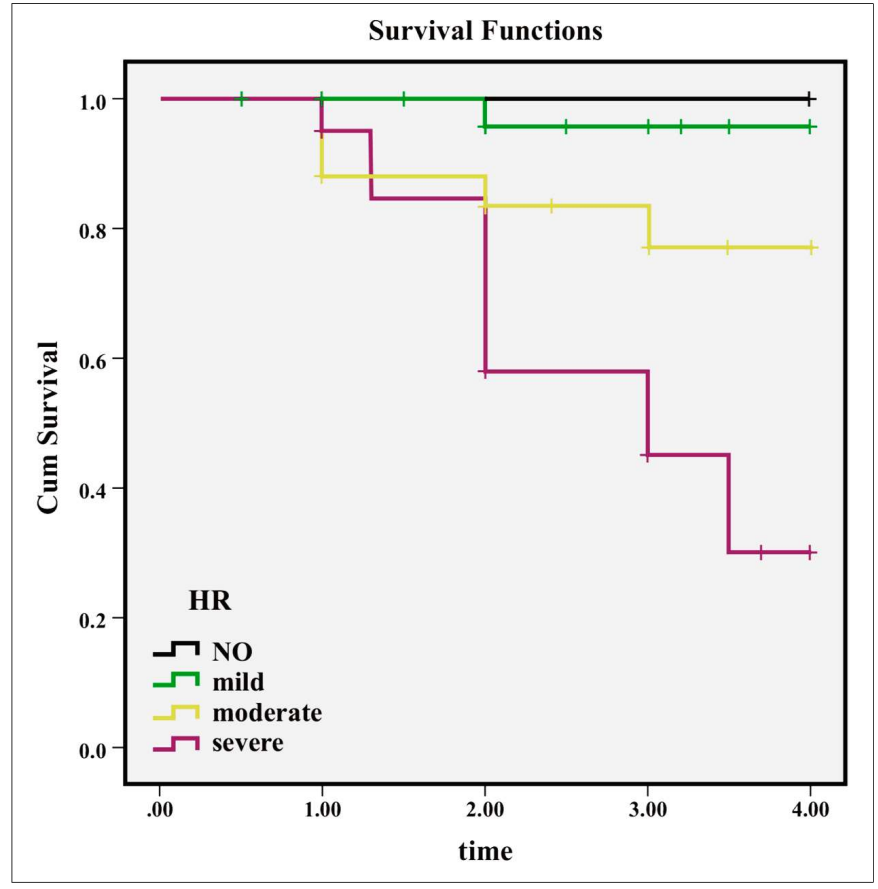

Figure 2: Kaplan-Meier curve for survival against hypertensive retinopathy and death.

The relative risk for overall complications and individual components of primary and secondary endpoints were calculated with severe HR by using regression model. The relative risk for complications increased by 3.17 times $\{\mathrm{Cl}-\mathrm{Exp}$ : (RR) 7.4-75.8\} with $\mathrm{p}<0.001$ with severe $\mathrm{HR}$. The calculated relative risk for various other complications are shown in Table III. Multivariate analysis for association between HR and post STEMI complication rates in successfully thrombolysed patients with multiple comorbid conditions is shown in Table IV. It showed that HR was associated with post STEMI complication rates $(p<0.001)$ independent of gender, diabetes and smoking, and family history.

Kaplan-Meier curve was plotted for survival of patients with HR for death as well as for complications. Death and complications increased while the survival decreased with the increase in stage of HR (Figures 1 and 2).

\section{DISCUSSION}

Hypertension has become the leading risk factor for cardiovascular disease worldwide. 12 Despite the rising trend towards hypertension awareness ranging from $72 \%$ in US to $62 \%$ in Australia, the BP control rates remained discouraging at $35 \%$ and $24 \%$, respectively. In South Asian countries like China and India, the reported control rates were $8 \%$ and $6 \%$, respectively. ${ }^{2}$ Control rates vary according to geographic region. ${ }^{13,14}$ National Health Survey of Pakistan reported an overall $18 \%$ of adults and $33 \%$ of adults above 45 years of age are hypertensive. It also stated that only $50 \%$ of hypertensive individuals were diagnosed and only half of those hypertensive individuals were on treatment. ${ }^{14}$ 
Previous studies have demonstrated the relationship between HR and cardiovascular disease.7,15,16 Retinal artery thickening had been associated with fibrous nodules formation and fibrinous degeneration in cerebral vessels. ${ }^{17}$ Association between retinal arteriolar-venular ratio and carotid intimal thickness had also been established in a study. ${ }^{18}$ Duncan et al. reported a twofold increase in cardiovascular disease with HR. ${ }^{19}$ Wong et al. in his case control study reported 1.8 times increased odds of coronary artery disease with HR. ${ }^{20}$ Atherosclerosis risk in communities (ARIC) documented 2.6 times increased risk of stroke with HR. ${ }^{21}$

The present study is unique in a sense that the association between HR and post-STEMI complications in successfully thrombolysed patients is documented. So far, the studies available were regarding new incidence of cardio-vascular disease and its relationship with HR or association of $\mathrm{HR}$ with angiographic severity of coronary artery disease. The present results were quite promising and demonstrated a very strong association between HR and post STEMI complications in successfully thrombolysed patients. Moreover, the incidence of post STEMI complications progressively increased from no HR to severe HR group. The overall death rate also increased while moving from no to severe HR. Relative risk of various complications with severe HR demonstrated that the relative risk of composite endpoints increased by 3.17 times $\{\mathrm{Cl}$ of $\operatorname{Exp}(R R) 7.4-75.8\}$ with severe HR. Relative risk of death also increased by 1.75 times $\{\mathrm{Cl}$ of $\operatorname{Exp}(\mathrm{RR})$ 2.57-9.12 $(p \leq 0.001)\}$ with severe HR. Multi-factorial analysis also proved an independent association between HR and post STEMI complications in this cohort study. KaplanMeier curve plotted for this study results showed an overall decreased survival with increasing grades of $\mathrm{HR}$.

The strengths of the study were its prospective cohort design, appropriate follow-up, and adequate sample size. However, the main limitation of this study was that fundoscopy was performed with a hand-held ophthalmoscope, which is not the gold standard.

So far, limited data was available regarding reversal of HR changes. However, studies are needed to be done to see whether reversal of HR reduces the risk of coronary artery disease and complications after acute coronary events or not.

\section{CONCLUSION}

HR was an independent risk factor for complications after successful thrombolysis of acute STEMI. HR also increased the relative risk of primary and secondary endpoints. Patients with acute STEMI should be routinely screened for HR to identify high risk individuals for early aggressive interventional management.

\section{REFERENCES}

1. Addo J, Smeeth L, Leon DA. Hypertensive target organ damage in Ghanaian civil servants with hypertension. PLoS One 2009; 4:e6672.

2. Kearney PM, Whelton M, Reynolds K, Muntner P, Whelton PK, $\mathrm{He} \mathrm{J}$. Global burden of hypertension: analysis of worldwide data. Lancet 2005; 365:217-23.

3. Devereux RB, Alderman MH. Role of preclinical cardiovascular disease in the evolution from risk factor exposure to development of morbid events. Circulation 1993; 88:1444-55.

4. Wong TY, Mitchell P. Hypertensive retinopathy. N Engl J Med 2004; 351:2310-7.

5. Wong TY, Klein R, Klein BE, Tielsch JM, Hubbard L, Nieto FJ. Retinal microvascular abnormalities and their relationship with hypertension, cardiovascular disease, and mortality. Surv Ophthalmol 2001; 46:59-80.

6. Shlomai G, Grassi G, Grossman E, Mancia G. Assessment of target organ damage in the evaluation and follow-up of hypertensive patients: Where do we stand? J Clin Hypertens (Greenwich) 2013; 15:742-7.

7. Wong TY, Mclntosh R. Hypertensive retinopathy signs as risk indicators of cardiovascular morbidity and mortality. $\mathrm{Br} \mathrm{Med}$ Bull 2005; 73-74:57-70

8. Williams B, Poulter NR, Brown MJ, Davis M, Mclnnes GT, Potter JF, et al. British Hypertension Society guidelines for hypertension management 2004 (BHS-IV): summary. BMJ 2004; 328:634-40

9. Chobanian AV, Bakris GL, Black HR, Cushman WC, Green LA, Izzo Jr JL, et al. The seventh report of the joint national committee on prevention, detection, evaluation, and treatment of high blood pressure: The JNC 7 report. JAMA 2003; 289: 2560-72.

10. Klein R, Klein BE, Moss SE. The relation of systemic hypertension to changes in the retinal vasculature: The Beaver Dam eye study. Trans Am Ophthalmol Soc 1997; 95:329-50.

11. Keith NM, Wagener HP, Barker NW. Some different types of essential hypertension: Their course and prognosis. Am J Med Sci 1974; 268:336-45.

12. Mohan S, Campbell NR. Hypertension management: Time to shift gears and scale up national efforts. Hypertension 2009; 53:450-1.

13. Kearney PM, Whelton M, Reynolds K, Muntner P, Whelton PK, $\mathrm{He} \mathrm{J}$. Global burden of hypertension: Analysis of worldwide data. Lancet 2005; 365:217-23.

14. Saleem F, Hassali AA, Shafie AA. Hypertension in Pakistan: Time to take some serious actions. Br J Gen Pract 2010; 60: 449-50.

15. Suri MF, Qureshi Al. Hypertensive retinopathy and risk of cardiovascular diseases in a national cohort. $J$ Vasc Interv Neurol 2008; 1:75-8.

16. Kabedi NN, Lepira FB, Kayembe TK, Kayembe DL, Mwanza JC. Hypertensive retinopathy and its association with cardiovascular, renal and cerebrovascular morbidity in Congolese patients. Cardiovasc J Afr 2014; 25:228-32

17. Goto I, Katsuki S, Ikui H, Kimoto K, Mimatsu T. Pathological studies on the intracerebral and retinal arteries in cerebro-vascular and noncerebrovascular diseases. Stroke 1975; 6: 263-9. 
18. Ikram MK, de Jong FJ, Vingerling JR, Witteman JC, Hofman A, Breteler MM, et al. Are retinal arteriolar or venular diameters associated with markers for cardiovascular disorders? The Rotterdam Study. Invest Ophthalmol Vis Sci 2004; 45 : 2129-34.

19. Duncan BB, Wong TY, Tyroler HA, Davis CE, Fuchs FD. Hypertensive retinopathy and incident coronary heart disease in high risk men. Br J Ophthalmol 2002; 86:1002-6.
20. Wong TY, Klein R, Nieto FJ, Klein BE, Sharrett AR, Meuer SM, et al. Retinal microvascular abnormalities and 10-year cardiovascular mortality: A population-based case-control study. Ophthalmology 2003; 110:933-40.

21. Wong TY, Klein R, Couper DJ, Cooper LS, Shahar E, Hubbard LD, et al. Retinal microvascular abnormalities and incident stroke: the atherosclerosis risk in communities study. Lancet 2001; 358:1134-40.

-.......... 